\title{
ĐÁNH GIÁ ĐẶC TÍNH PROBIOTIC CỦA VI KHUẨN GRAM DƯƠNG PHÂN LẬP TÙ ĐƯờnG TIÊU HOÁ GÀ
}

\author{
NGÔ CHÍ CÔNG, TRỊNH NGỌC NAM \\ Viện công nghệ Sinh học và Thực phẩm, Trương Đại học Công nghiệp Thành phố Hồ Chí Minh \\ trinhngocnam@iuh.edu.vn
}

Tóm tắt. Probiotic được ứng dụng ngày càng rộng rãi trong ngành thực phẩm, dược phẩm, chăn nuôi. Nguồn vi sinh vật có đặc tính probiotic từ trong tự nhiên rất đa dạng và phong phú đặc biệt là trong đường ruột của vật nuôi. Nghiên cứu này được thực hiện nhằm tuyển chọn các chủng vi khuẩn có đặc tính probiotic từ đường tiêu hoá gà nuôi tự nhiên. Từ 50 chủng vi khuẩn phân lập được từ ruột gà, nghiên cứu đã tuyển chọn được 5 chủng vi khuẩn là $\mathrm{C} 19, \mathrm{C} 31, \mathrm{C} 38, \mathrm{C} 43$ và $\mathrm{C} 47$ có đặc tính probiotic tốt, phát triển được ở môi trường có $\mathrm{pH}$ dưới 3 , chịu được muối mật đến nồng độ $1,5 \%$, đối kháng yếu hoặc trung bình với một số loại vi khuẩn gây bệnh, có khả năng hình thành bào tử dưới tác dụng của xử lý nhiệt. Dựa vào giải trình tự vùng gen $16 \mathrm{~S} r R N A$, nghiên cứu đã xác định 5 chủng vi khuẩn tuyển chọn đều thuộc chi Bacillus Những kết quả của nghiên cứu này cho thấy tiềm năng ứng dụng của vi khuẩn probiotic phân lập từ đường tiêu hoá gà trong chăn nuôi.

Từ khóa. vi khuẩn probiotic, Bacillus, đường tiêu hoá gà, bào tử.

\section{EVALUATION OF PROBIOTIC CHARACTERISTICS OF GRAM POSITIVE BACTERIA ISOLATED FROM DIGESTIVE TRACT OF CHICKENS}

\begin{abstract}
Probiotic bacteria are widely used in food, pharmaceutical products and considered as one of the main components of livestock industry. Microbial sources with probiotic properties are abundant in nature, especially in poultry gastrointestinal tract. The study was conducted to isolate bacterial strains with probiotic properties from digestive tract of chickens. Among 50 isolated strains, 5 bacterum strains with good probiotic characteristics were selected, including C19, C31, C38, C43 and C47. These strains were able to growth in low $\mathrm{pH}$ condition, withstand bile concentration over $1 \%$, weak or moderate antagonism with the pathogenic bacteria, and showed spore forming capable under heat treatment. Using sequencing of $16 S$ rRNA region, the selected strains were indicated belong to Bacillus genus. Taken together, the results of this study showed the applicability of the probiotic bacteria isolated from chicken gastrointestinal tract for the poultry industry.
\end{abstract}

Keywords. probiotic bacteria, Bacillus, digestive tract of chickens, spores.

\section{GIỚI THIÊU}

Vi sinh vật probiotic là những chủng vi khuẩn, nấm mốc, nấm men đơn bào không sinh độc tố với vật chủ [1]. Các chủng vi sinh vật probiotic các đặc tính đặc trưng, bao gồm có khả năng chịu được muối mật trong đường tiêu hoá của vật nuôi; chịu được môi trường có $\mathrm{pH}$ thấp, thường từ 1.5-3; đối kháng tốt với một số vi sinh vật gây bệnh đường ruột như Escherichia coli, Salmonella, Staphylococcus, Campylobacteria; bám dính tốt vào tế bào biểu mô ruột; thích nghi với một số loại kháng sinh thông dụng; và đặc biệt có hiệu quả kích thích quá trình tiêu hoá thức ăn, hấp thu chất dinh dưỡng của vật chủ [2].

Probiotic được ứng dụng ngày càng rộng rãi trong ngành thực phẩm, dược phẩm, chăn nuôi. Sử dụng probiotic một cách hợp lý giúp vật nuôi khỏe mạnh, tăng sức đề kháng, cạnh tranh với các vi sinh vật gây bệnh, giúp chuyển đổi hệ số tiêu hóa thức ăn tốt hơn và giảm dần lượng thuốc, kháng sinh sử dụng, đặc biệt đối với ngành chăn nuôi công nghiệp [3]. Nguồn vi sinh vật có đặc tính probiotic từ trong tự nhiên rất đa dạng và phong phú đặc biệt là trong đường ruột của vật nuôii. Nghiên cứu của Patterson (2003) đã xác định có từ $20-50 \%$ số loài vi khuẩn trong đường tiêu hoá là probiotic. Trong số các chủng vi sinh vật probiotic phổ biến, có thể kể đến các loài thuộc chi Lactobacillus, Bifidobacterium, Bacillus, và một số loài nấm men thuộc chi Saccharomyces [4]. 
Các chủng vi khuẩn probiotic thuộc chi Bacillus được sử dụng rộng rãi nhất hiện nay trong chăn nuôi và nuôi trồng thuỷ sản. Thuộc nhóm trực khuẩn sinh bào tử, sống hiếu khí tùy tiện, vi khuẩn Bacillus phân bố rộng khắp trong tự nhiên và trong cơ thể người và động vật, thích nghi tốt với nhiều điều kiện môi trường khắc nghiệt. Nhiệt độ sinh trưởng tối ưu của các chủng Bacillus từ $30-45^{\circ} \mathrm{C}$, nhưng có khả năng chịu nhiệt lên đến $65^{\circ} \mathrm{C}$. Các loài vi khuẩn thuộc chi Bacillus sinh trưởng trong khoảng $\mathrm{pH}$ rộng từ $2-11$, có khả năng sinh bacteriocin ức chế một số vi sinh vật gây bệnh đường ruột đặc biệt là E. coli [5].

Nghiên cứu hiện tại được thực hiện nhằm tuyển chọn những chủng vi khuẩn có đặc tính probiotic từ đường ruột của gà nuôi thả tự nhiên tại vùng nông thôn Việt Nam để hướng đến việc ứng dụng tạo ra chế phẩm probiotic bổ sung trong thức ăn chăn nuôi.

\section{VậT LIỆU VÀ PHƯƠNG PHÁP NGHIÊN CỨU}

\subsection{Vật liệu nghiên cứu}

Hệ tiêu hoá được tách từ gà 3-5 tháng tuổi nuôi thả tự nhiên tại tỉnh Bình Định. Sau khi thu nhận, hệ tiêu hoá gà được rửa bằng nước cất vô trùng. Mẫu ruột nguyên vẹn từ phần dạ dày cơ đến ổ nhớp được tách và đồng nhất trong nước muối sinh lý bằng máy dập mẫu BagMixer 400P (Interscience, Pháp), sử dụng để phân lập các chủng vi sinh vật.

Các chủng vi khuẩn kiểm định, bao gồm E. coli, Salmonella sp., Staphylococcus aureus sử dụng trong nghiên cứu được cung cấp bởi Viện Pasteur thành phố Hồ Chí Minh.

\subsection{Phương pháp nghiên cứu}

\subsubsection{Phân lập vi khuẩn probiotic}

Mẫu dịch ruột gà đồng nhất được pha loãng với với nước muối sinh lý và cấy trải trên môi trường MRS agar (Titan, Ẩn Độ) và LB agar (Merck, Đức). Các đĩa trải được nuôi ủ ở $37^{\circ} \mathrm{C}$, trong tối, với điều kiện hiếu khí và kỵ khí với nồng độ $5 \% \mathrm{CO}_{2}$, trong 24 giờ. Khuẩn lạc đơn trên các đĩa petri được cấy phân lập riêng, tiến hành quan sát hình dạng khuẩn lạc, hình thái tế bào và nhuộm Gram. Các chủng khác biệt được lưu trữ ở $4^{\circ} \mathrm{C}$ sử dụng cho các nghiên cứu khảo sát đặc tính probiotic.

\subsubsection{Khảo sát khả năng chịu pH thấp của các chủng vi khuẩn phân lập}

Các củng vi khuẩn nghiên cứu được nuôi tăng sinh trên môi trường LB hoặc MRS trong 18 giờ ở $37^{\circ} \mathrm{C}$ trên máy lắc vòng với tốc độ 150 vòng/phút. Dịch vi khuẩn tăng sinh được xác định độ đục bằng đo $\mathrm{OD}$ ở bước sóng $621 \mathrm{~nm}$ và được bổ sung vào trong các môi trường nuôi cấy đã được điều chỉnh đến các $\mathrm{pH}$ khác nhau, từ $\mathrm{pH} 1,5$ đến $\mathrm{pH} 6,0$ để đặt được giá trị $\mathrm{OD}$ ban đầu khoảng 0,01 . Sau 3 giờ nuôi cấy ở $37^{\circ} \mathrm{C}$ trên máy lắc vòng với tốc độ 150 vòng/phút, sự sinh trưởng của vi khuẩn được đánh giá bởi đo đo $\mathrm{OD}$.

\subsubsection{Khảo sát khả năng chịu muối mật}

Dịch vi khuẩn sau tăng sinh được bổ sung vào các môi trường nuôi LB hoặc MRS có nồng độ muối mật từ 0,5 đến $2 \%$ để đạt được giá trị $\mathrm{OD}_{621 \mathrm{~nm}}$ ban đầu khoảng 0,05 . Sau 10 giờ nuôi cấy ở $37^{\circ} \mathrm{C}$ trên máy lắc vòng với tốc độ 150 vòng/phút, sự sinh trưởng của vi khuẩn được xác định bởi đo $\mathrm{OD}_{621 \mathrm{~nm}}$.

\subsubsection{Khảo sát khả năng đối kháng với vi khuẩn gây bệnh}

Các chủng vi khuẩn gây bệnh gồm Staphylococcus aureus, Escherichia coli, Salmonella typhimurium, được nuôi tăng sinh trên môi trường $\mathrm{LB}$ trong $18 \mathrm{~h}$ ở $37^{\circ} \mathrm{C}$ trên máy lắc vòng với tốc độ $150 \mathrm{vòng} / \mathrm{phút}$. Dịch vi khuẩn được pha loãng để đạt được độ đục tương đương 0.5 độ McFaland [6] và được trải đều một lượng $0.1 \mathrm{ml}$ lên bề mặt môi trường BHI agar. Các chủng vi khuẩn nghiên cứu nuôi tăng sinh được pha loãng đến OD 0,05 , được bổ sung vào lỗ thạch trên môi trường cấy trải vi khuẩn gây bệnh với $150 \mu 1$ dịch vi khuẩn/lỗ thạch. Đối chứng dương là đĩa giấy tẩm kháng sinh gentamycin $(10 \mu \mathrm{g})$, đối chứng âm là $150 \mu \mathrm{l}$ nước muối sinh lý vô trùng. Sau 24 giờ nuôi cấy ở $37^{\circ} \mathrm{C}$, đo kích thước vòng vô khuẩn để xác định khả năng đối kháng vi khuẩn gây bệnh.

\subsubsection{Khảo sát khả năng hình thành bảo tử}

Khả năng hình thành bào tử được thực hiện dựa trên nguyên tắc tác động của môi trường không thuận lợi về nhiệt độ [7]. Các khoảng nhiệt độ và thời gian được thực hiện dựa theo nguyên cứu của Setlow (1970) [7]. Các chủng vi khuẩn được nuôi tăng sinh trong môi trường $\mathrm{LB}$ trong 18 giờ ở $37^{\circ} \mathrm{C}$ và được pha loãng đến $\mathrm{OD}_{621 \mathrm{~nm}} 0,05$. Xác định mật độ tế bào vi khuẩn trong dịch pha loãng bằng phương pháp đếm khuẩn lạc. Khả năng sinh bào tử của các chủng vi khuẩn được thực hiện bằng cách bổ sung $1 \mathrm{ml}$ sinh khối đã được 
chuẩn bị vào môi trường Difco Sporulation medium (DSM), gia nhiệt đến mức $40^{\circ} \mathrm{C}, 50^{\circ} \mathrm{C}, 60^{\circ} \mathrm{C}$ trong 12 giờ để kích thích hình thành bào tử và được đun ở $70^{\circ} \mathrm{C}$ trong 30 phút để tiêu diệt hoàn toàn tế bào sống. Một lượng $0,1 \mathrm{ml}$ dịch vi khuẩn sau đun được cấy trải trên môi trường $\mathrm{LB}$ agar, nuôi ủ $35^{\circ} \mathrm{C}$ trong 24 giờ để xác định mật độ vi khuẩn. Tỉ lệ hình thành bào tử dưới ảnh hưởng của các mức xử lý nhiệt được xác định bằng cách đếm trực tiếp bào tử trên kính hiển vi sau khi nhuộm bào tử trong các dịch vi khuẩn bằng thuốc nhuộm malachite green $0,5 \%$ và safranin $2,5 \%$.

\subsection{6 Định danh các chủng vi khuẩn probiotic bằng phương pháp giải trình tự vùng gen 16S rRNA}

Các chủng vi khuẩn được tách chiết DNA tổng số cách ly giải tế bào trong đệm ly giải chứa $10 \%$ SDS 20 $\mathrm{mg} \mathrm{ml}^{-1}$ proteinase $\mathrm{K}$ ở $37^{\circ} \mathrm{C}$ trong 1 giờ. Hỗn hợp được bổ sung $800 \mu \mathrm{l}$ chloroform : isoamyl alcohol (tỉ lệ $24: 1)$, và ly tâm ở tốc độ 13.000 vòng/phút trong 10 phút ở $4^{\circ} \mathrm{C}$. Dịch nổi được thu nhận và bổ sung 800 $\mu 1$ isopropanol lạnh để tủa DNA. Tủa DNA tiếp tục được hoà tan vào $800 \mu 1$ ethanol $70 \%$ và ly tâm ở 13.000 vòng/phút trong 10 phút ở $4^{\circ} \mathrm{C}$. Tủa DNA được thu nhận và hoà vào $50 \mu 1$ dung dịch $\mathrm{TE}$ trước khi bảo quản ở $-20^{\circ} \mathrm{C}$.

Mẫu DNA tổng số của vi khuẩn được tiến hành khuếch đại gen $16 \mathrm{~S} r R N A$ bằng kỹ thuật PCR với mồi xuôi 5'AGCAGTACTGGAATCTTCCA3' và mồi ngược 5'ATTCCACCGCTACACATG3' [8]. Thành phần phản ứng trong thể tích phản ứng $30 \mu 1$ bao gồm: $15 \mu 1$ Go Taq Green Master Mix (Promega, Hoa Kỳ), $5 \mu 1$ mồi xuôi, $5 \mu 1$ ngược có nồng độ $10 \mu \mathrm{M}$ và $5 \mu 1$ mẫu DNA. Chu kỳ nhiệt của phản ứng PCR được thực hiện trên máy Mastercycler (Eppendorf, Đức) gồm các bước: 3 phút ở $94^{\circ} \mathrm{C}$; lặp lại 30 - 33 chu kỳ của các bước biến tính mạch khuôn $\left(30\right.$ giây ở $\left.94^{\circ} \mathrm{C}\right)$, bắt cặp mồi $\left(30\right.$ giây ở $\left.50-57^{\circ} \mathrm{C}\right)$ và tổng hợp mạch mới $(1$ phút ở $72^{\circ} \mathrm{C}$ ); phản ứng hoàn thiệt ở $72^{\circ} \mathrm{C}$ trong 10 phút. Kiểm tra các sản phẩm của PCR bằng điện di điện di trên gel agarose 1\%. Sản phẩm sau khi PCR được giải trình tự theo phương pháp Sanger tại Công ty Nam Khoa Biotek (Thành phố Hồ Chí Minh). Độ chính xác của trình tự kiểm tra và hiệu chỉnh bằng phần mềm Finch Tv 1.4 và Seaview 4.7. Dữ liệu gen $16 \mathrm{~S}$ rRNA các chủng vi khuẩn tham chiếu được thu nhận từ ngân hàng dữ liệu NCBI (Bảng 1), trong đó vi khuẩn $E$. coli được sử dụng như nhóm ngoại. Cây phát sinh loài được xây dựng dùng phần mềm MrBayes 3.2.6 bằng phương pháp neighbor-joining với bootstrap 1000 lần.

Bảng 1: Dữ liệu trình tự gen $16 \mathrm{~S}$ rRNA của các chủng vi khuẩn tham chiếu từ NCBI sử dụng để xây dựng cây phát sinh loài

\begin{tabular}{lc}
\hline Chủng vi khuẩn tham chiếu & Mã truy cập gen \\
\hline Bacillus cereus & MH279684.1 \\
Bacillus megaterium & KC595874.1 \\
Bacillus halodurans & EF113301.1 \\
Bacillus firmus & AJ509007.1 \\
Bacillus thuringiensis & KY622894.1 \\
Bacillus toyonensis & KY352823.1 \\
Bacillus tequilensis & JX898005.1 \\
Bacillus subtilis & AJ277906.1 \\
Bacillus wiedmannii & MH178362.1 \\
Bacillus albus & MH475941.1 \\
Bacillus mycoides & MH169305.1 \\
Bacillus anthracis & MH135299.1 \\
Bacillus paramycoides & MK511836.1 \\
Bacillaceae bacterium & KM187321.1 \\
Paenibacillus dendritiformis & MG981756.1 \\
Bacillus licheniformis & MH150817.1 \\
Bacillus velezensis & MN062956.1 \\
Escherichia coli & CP058023.1 \\
\hline
\end{tabular}




\subsubsection{Phương pháp xử lý số liệu}

Các nghiên cứu được thực hiện lặp lại 3 lần, kết quả trình bày là trung bình cộng $\pm \mathrm{SD}$. Số liệu nghiên cứu được xử lý so sánh bằng phần mềm kê SPSS Statistics 20 (IBM, Hoa Kỳ) với giá trị $P$-value $\leq 0,05$.

\section{KẾT QUẢ VÀ THẢO LUẬN}

\subsection{Kết quả phân lập các chủng vi khuẩn từ ruột gà}

Từ các mẫu ruột thu nhận từ gà nuôi thả tự nhiên, đã phân lập được 50 chủng vi khuẩn có hình dạng khuẩn lạc, hình dạng vi thể và đặc tính nhuộm Gram khác nhau (Hình 1). Trong số này, có 30 chủng vi khuẩn là Gram dương với 22 chủng có tế bào dạng hình que, 6 chủng dạng hình cầu, 1 chủng hình oval và 1 chủng hình dấu phẩy. Ngoại trừ một vài chủng vi khuẩn Gram âm có đặc tính probiotic như E. coli Nisle 1917, nhiều công bố gần đây đều xác định hầu hết các vi khuẩn probiotic thuộc nhóm vi khuẩn Gram dương [9, $10,11]$. Trong nghiên cứu này, các chủng vi khuẩn Gram+ được lựa chọn cho các nghiên cứu khảo sát đặc tính probiotic tiếp theo.
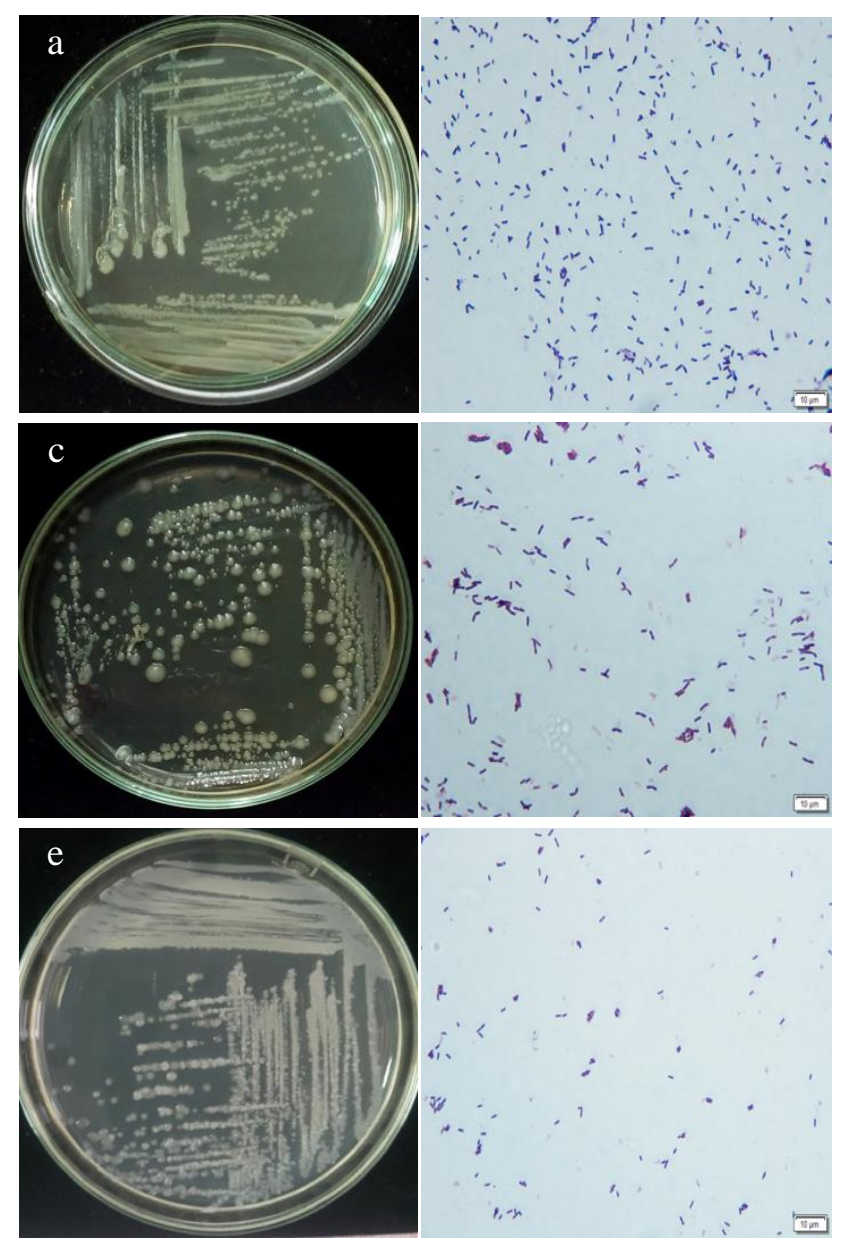
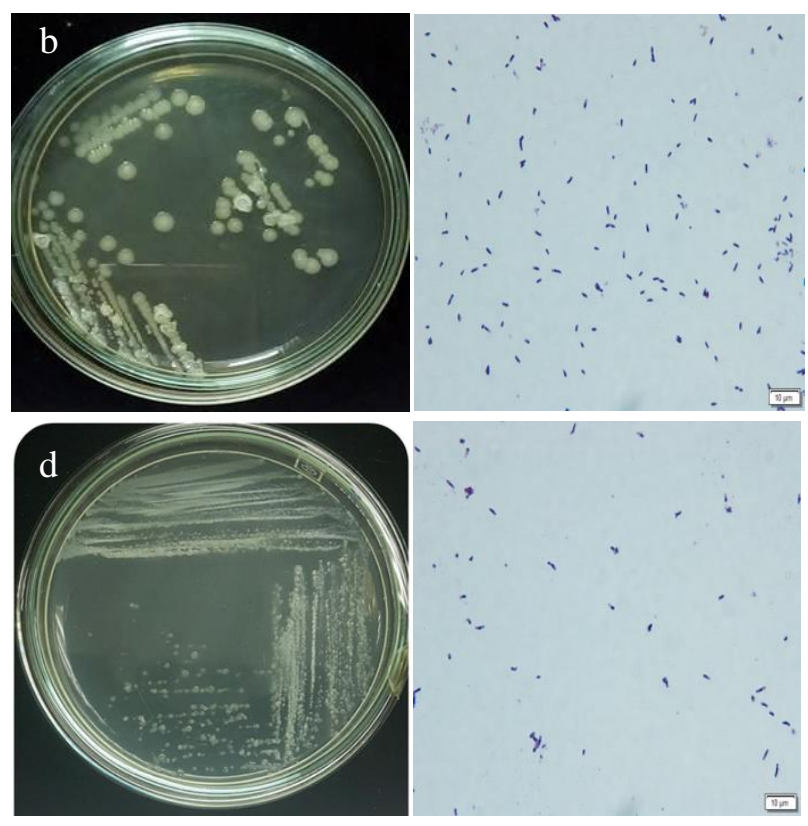

Hình 1: Hình dạng khuẩn lạc và nhuộm Gram tế bào một số chủng vi khuẩn phân lập từ ruột gà. (a) chủng $\mathrm{C} 19$, (b) chủng $\mathrm{C} 31$, (c) chủng $\mathrm{C} 37$, (d) chủng $\mathrm{C} 38$, (e) chủng $\mathrm{C} 47$ 


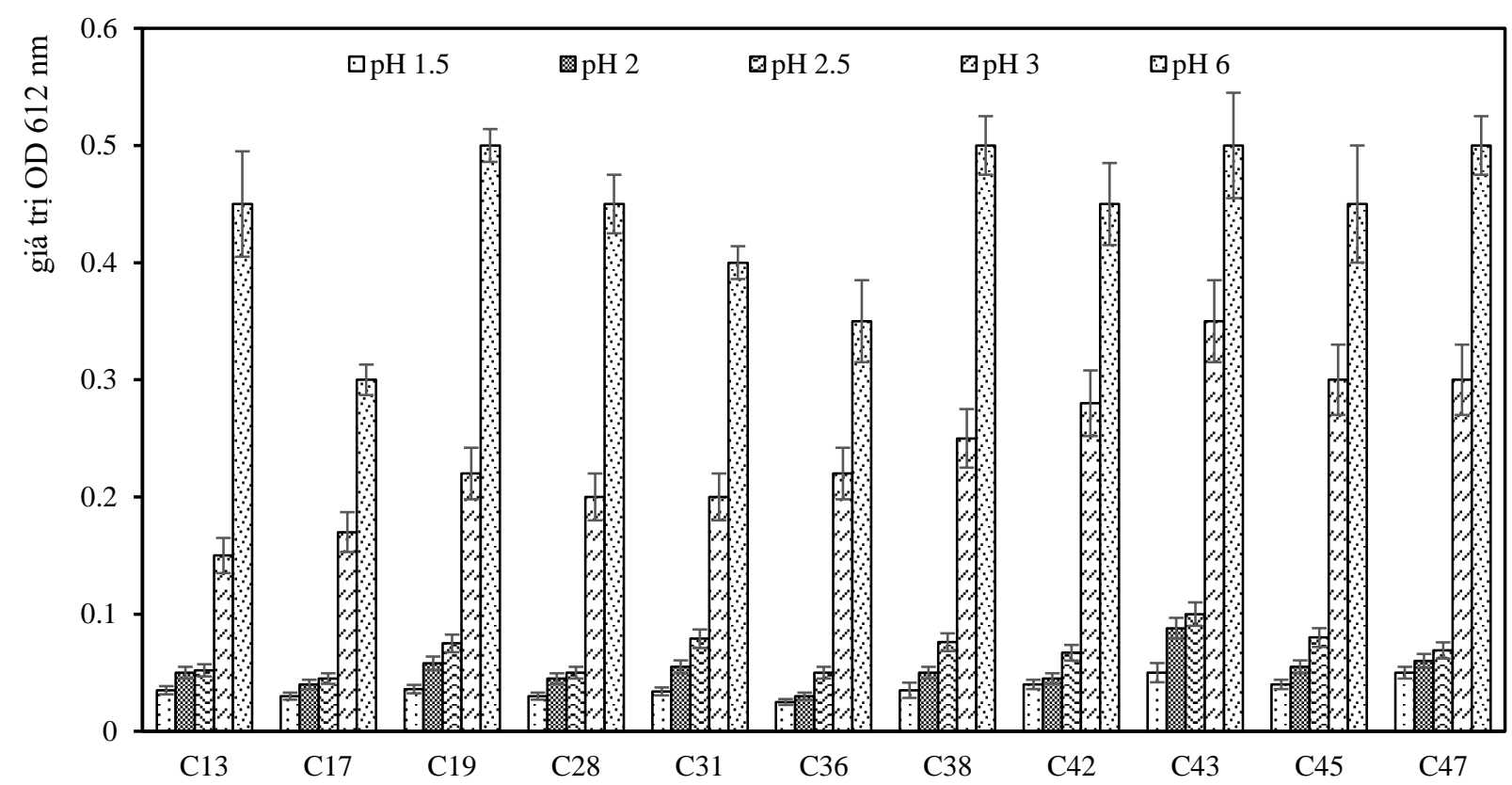

Hình 2: Sự phát triển của các chủng vi khuẩn phân lập từ đường tiêu hoá của gà ở các môi trường nuôi cấy có pH khác nhau.

\subsection{Kết quả khảo sát khả năng chịu acid của các chủng vi khuẩn}

Các chủng vi khuẩn probiotic có đặc tính quan trọng là chịu được acid thấp, là điều kiện đặc trưng trong phần trên đường tiêu hoá của vật nuôi [12]. Do vậy, từ các chủng vi khuẩn phân lập được, tiến hành khảo sát khả năng sống sót trong môi trường $\mathrm{pH}$ thấp $(\mathrm{pH} 1,5 ; 2 ; 2,5 ; 3$ và 6$)$. Trong số 30 chủng vi khuẩn Gram+ thử nghiệm, chỉ 11 chủng có khả năng phát triển ở pH dưới 3. Các chủng vi khuẩn được đặt tên $\mathrm{C} 43, \mathrm{C} 47$, $\mathrm{C} 45, \mathrm{C} 31, \mathrm{C} 38$ và $\mathrm{C} 19$ phát triển tốt ở tất cả các $\mathrm{pH}$ thử nghiệm, sắp xếp theo mức độ chịu $\mathrm{pH}$ thấp từ cao đến thấp (Hình 2).

Nghiên cứu của Hyronimus et al. (2000) và Tee et al. (2013) cho thấy, các chủng vi khuẩn probiotic thuộc chi Lactobacllus có khả năng chịu được $\mathrm{pH}$ thấp ở mức $\mathrm{pH} 1,5$ đến $\mathrm{pH} 2,5$ trong thời gian 2 giờ $[12,13]$. Đối với các chủng vi khuẩn thuộc chi Bacillus được xác định trong nghiên cứu của Patel et al. (2009) có khả năng chịu được mức $\mathrm{pH}$ thấp từ $\mathrm{pH} 1,5$ đến $\mathrm{pH} 2,5$ chỉ trong thời gian 90 phút đến 120 phút [14]. Trong nghiên cứu này, các chủng vi khuẩn $\mathrm{C} 19, \mathrm{C} 31, \mathrm{C} 38, \mathrm{C} 43$ và $\mathrm{C} 47$ có thể chịu được mức $\mathrm{pH} 1,5$ trong thời gian lâu hơn (3 giờ).

\subsection{Kết quả khảo sát khả năng chịu muối mật của các chủng vi khuẩn}

Muối mật ngoài chức năng hỗ trợ tiêu hóa thức ăn còn được xem như một chất kháng khuẩn trong đường tiêu hóa, bảo vệ ruột khỏi sự xâm nhập của các vi sinh vật gây bệnh [15]. Khả năng sống sót dưới tác dụng của muối mật là một trong những đặc tính quan trọng của vi sinh vật probiotic [13]. Đặc tính khả năng chịu muối mật của 11 chủng C13, C17, C19, C28, C31, C36, C38, C42, C43, C45, C47 được khảo sát ở các nồng độ muối mật $0 ; 0,3 ; 0,5 ; 1$, và $1,5 \%$. Theo kết quả trình bày ở Hình 3 , sau 10 giờ nuôi cấy, ở môi trường nuôi cấy có nồng độ muối mật $0,5 \%$ chỉ có 6 chủng vi khuẩn, bao gồm $\mathrm{C} 13, \mathrm{C} 19, \mathrm{C} 31, \mathrm{C} 38, \mathrm{C} 43$ và $\mathrm{C} 47$ có khả năng sinh trưởng (giá trị $\mathrm{OD}_{612 \mathrm{~nm}}>0,05$ ); các chủng khác bị ức chế hoặc chống chịu (giá trị $\left.\mathrm{OD}_{612 \mathrm{~nm}} \leq 0,05\right)$. Ở nồng độ muối mật $1,5 \%$ chỉ có 2 chủng vi khuẩn $\mathrm{C} 19$ và $\mathrm{C} 38$ sinh trưởng được (giá trị $\mathrm{OD}>0,05) ; 3$ chủng còn lại, gồm $\mathrm{C} 31, \mathrm{C} 43$, và $\mathrm{C} 47$, có khả năng chống chịu (giá trị $\mathrm{OD}_{612 \mathrm{~nm}} \sim 0,05$ ). 


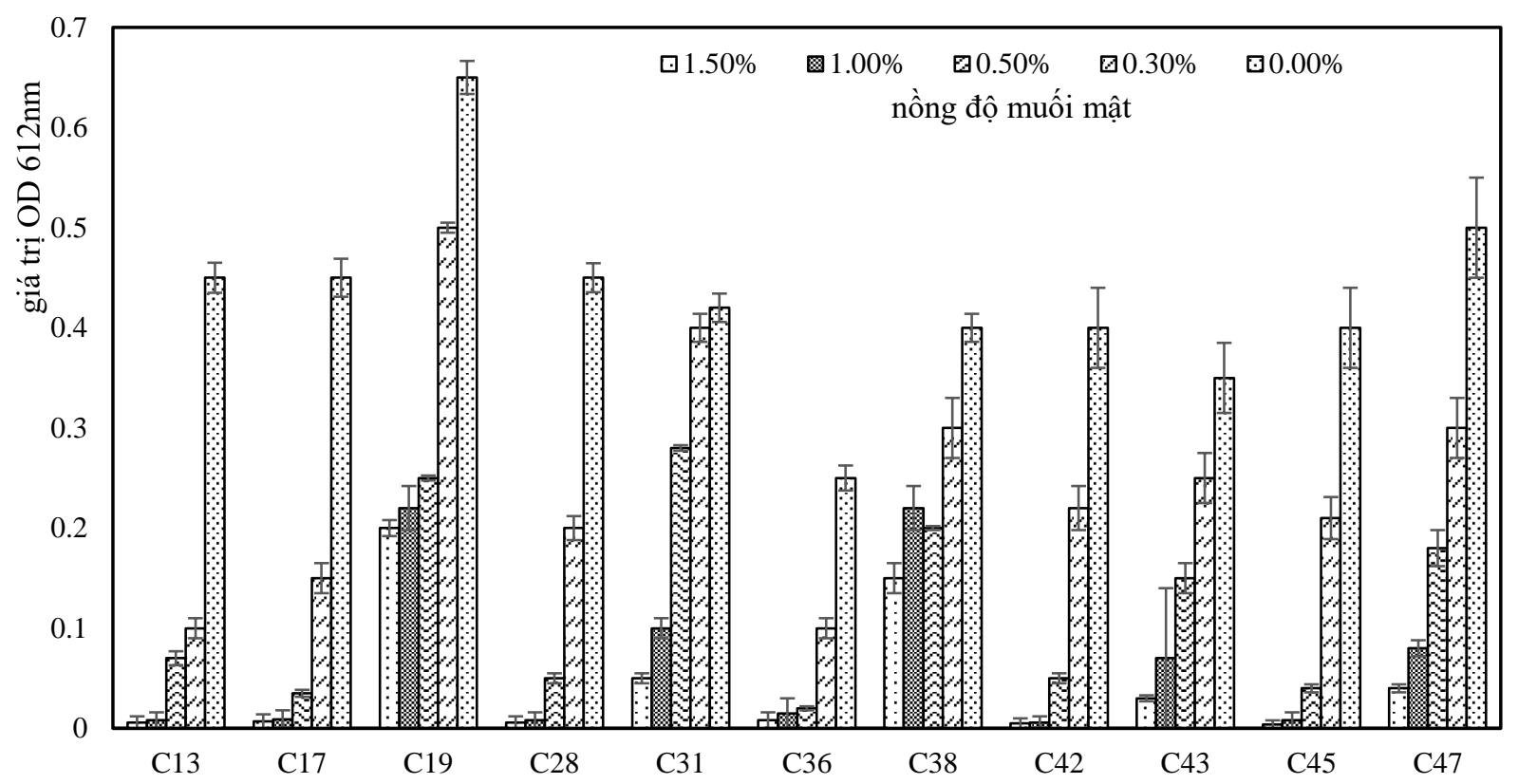

Hình 3: Sự phát triển của các chủng vi khuẩn phân lập từ đường tiêu hoá của gà ở các môi trường nuôi cấy có bổ sung muối mật với các nồng độ khác nhau

Các chủng vi sinh vật nuôi cấy môi trường có nồng độ muối mật cao sẽ gia tăng độ thẩm thấu trong tế bào do hấp thu natri glycocholate và natri taurocholate có trong muối mật. Sự gia tăng này làm phá vỡ hoặc làm biến tính cấu trúc của màng nguyên sinh và các protein xuyên màng. Đối với các chủng vi khuẩn có khả năng chịu muối mật sẽ tiết ra một loại protein đặc hiệu để phòng ngừa sự biến tính các protein khác và giúp sửa chữa lại các protein đã bị biến tính, nhờ đó có khả năng sống sót được trong môi trường có nồng độ muối mật cao [16, 17]. Nghiên cứu của Nguyễn Văn Thanh và Trần Thu Hoa (2007) cho thấy Bacillus subtilis chịu được môi trường có nồng độ muối mật từ $1 \%-2 \%$ trong 10 giờ, trong khi đó vi khuẩn Lactobacillus acidophilus không có khả năng phát triển ở những nồng độ muối mật này [18]. Kết quả tương tự cũng được nhật thấy trong nghiên cứu của Pan et al. (2009) [17], Trần Quốc Việt và cộng sự (2009) [19], các chủng vi khuẩn probiotic có khả năng tồn tại và phát triển được trong môi trường có nồng độ muối mật từ $0,3 \%-0,5 \%$. Như vậy, trong nghiên cứu này, ngoại trừ 5 chủng vi khuẩn $\mathrm{C} 19, \mathrm{C} 31, \mathrm{C} 38, \mathrm{C} 43$ và $\mathrm{C} 47$, các chủng vi khuẩn khác chỉ phát triển được ở môi trường có nồng độ muối mật thấp.

\subsection{Kết quả khảo sát khả năng đối kháng với vi sinh vật gây bệnh}

Ngoài khả năng chịu pH thấp, chịu nồng độ muối mật cao thì khả năng cạnh tranh và ức chế các vi sinh vật gây bệnh, giúp cân bằng hệ vi sinh vật đường ruột cũng là một đặc tính quan trọng của vi khuẩn probiotic. Khảo sát khả năng đối kháng với 3 chủng vi khuẩn gây bệnh bao gồm Escherichia coli, Salmonella typhimurium và Staphylococus aureus bằng phương pháp lỗ thạch được thực hiện với các chủng vi khuẩn C19, C31, C38, C43 và C47.

Bảng 2: Hoạt tính đối kháng các chủng vi khuẩn gây bệnh của các chủng vi khuẩn phân lập từ đường tiêu hoá gà

\begin{tabular}{cccccccc}
\hline \multirow{2}{*}{$\begin{array}{c}\text { Vi khuẩn kiềm } \\
\text { nghiệm }\end{array}$} & \multicolumn{7}{c}{ Hoạt tính đối kháng, $\mathrm{D}-\mathrm{d}(\mathrm{cm})$} \\
\cline { 2 - 7 } & Đối chứng + Đối chứng - & $\mathrm{C} 19$ & $\mathrm{C} 31$ & $\mathrm{C} 38$ & $\mathrm{C} 43$ & $\mathrm{C} 47$ \\
\hline S. aureus & $0,9^{\mathrm{d}} \pm 0,1$ & $0,0^{\mathrm{a}} \pm 0$ & $0,2^{\mathrm{b}} \pm 0,02$ & $0,15^{\mathrm{ab}} \pm 0,05$ & $0,1^{\mathrm{ab}} \pm 0,02$ & $0,2^{\mathrm{b}} \pm 0,1$ & $0,4^{\mathrm{c}} \pm 0,1$ \\
E. coli & $0,8^{\mathrm{c}} \pm 0,05$ & $0,0^{\mathrm{a}} \pm 0$ & $0,2^{\mathrm{b}} 0,02$ & $0,2^{\mathrm{b}} \pm 0,02$ & $0,1^{\mathrm{a}} \pm 0$ & $0,2^{\mathrm{b}} \pm 0,05$ & $0,8^{\mathrm{c}} \pm 0,02$ \\
S. typhimurium & $0,9^{\mathrm{c}} \pm 0,05$ & $0,0^{\mathrm{a}} \pm 0$ & $0,2^{\mathrm{b}} \pm 0,02$ & $0,2^{\mathrm{b}} \pm 0,02$ & $0,2^{\mathrm{b}} \pm 0$ & $0,2^{\mathrm{b}} \pm 0$ & $1,2^{\mathrm{d}} \pm 0,1$ \\
\hline
\end{tabular}


Các chữ cái khác nhau đi kèm giá trị trung bình trong cùng hàng biểu thị sự khác biệt có ý nghĩa thống kê ở mức $\mathrm{P}$-values $\leq 0,05$. D: đường kính vòng vô khuẩn; $\mathrm{d}$ : đường kính lỗ thạch; $\mathrm{D}-\mathrm{d} \geq 2,5 \mathrm{~cm}$ : kháng rất mạnh, $\mathrm{D}-\mathrm{d} \geq 2,0 \mathrm{~cm}$ : kháng mạnh, $\mathrm{D}-\mathrm{d} \geq 1,5 \mathrm{~cm}$ : kháng trung bình, $\mathrm{D}-\mathrm{d}<1,0 \mathrm{~cm}$ : kháng yếu

Hầu hết các chủng vi khuẩn khảo sát đều cho thấy khả năng kháng yếu với các chủng vi khuẩn gây bệnh, ngoại trừ chủng vi khuẩn $\mathrm{C} 47$. Chủng vi khuẩn $\mathrm{C} 47$ kháng trung bình đối với vi khuẩn $S$. typhimurium (Bảng 2, Hình 4).
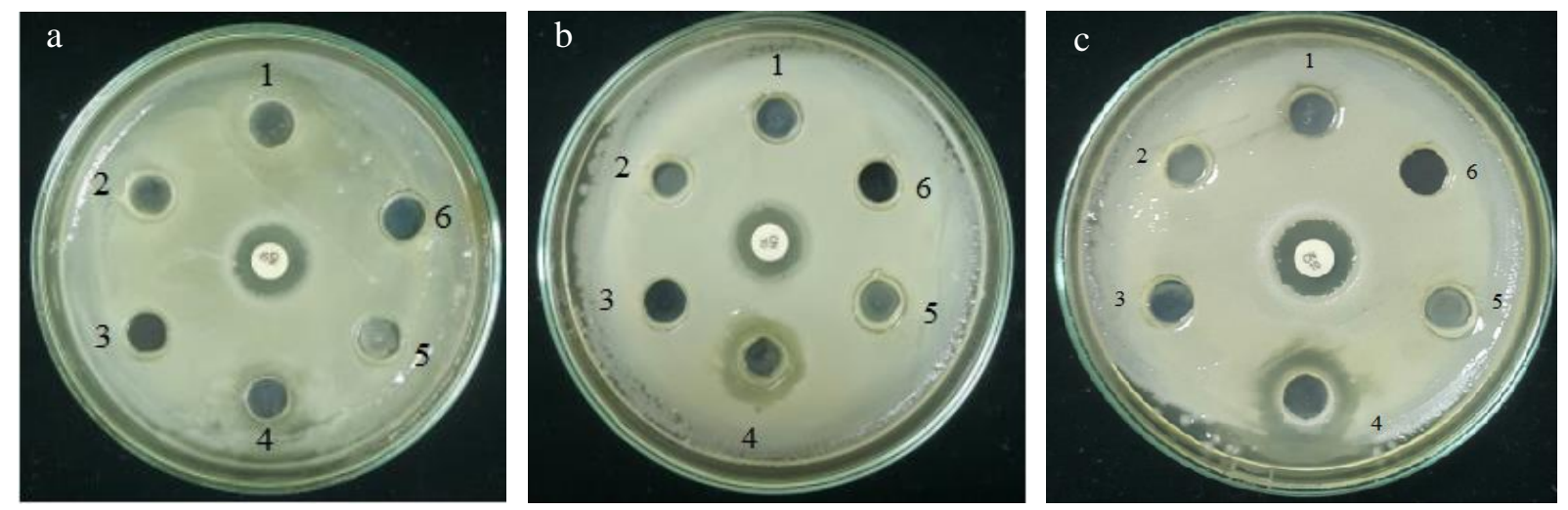

Hình 4: Khả năng kháng vi sinh vật gây bệnh của các chủng vi khuẩn phân lập từ đường tiêu hoá gà. (a) thử nghiệm kháng $S$. aureus; (b) thử nghiệm kháng $E$. coli; (c) thử nghiệm kháng $S$. typhimureum. (1) chủng C38, (2) chủng C43, (3) chủng $\mathrm{C} 19$, (4) chủng $\mathrm{C} 47,(5)$ chủng $\mathrm{C} 31$, (6) đối chứng âm, đối chứng dương: giấy tẩm gentamicin ở giữa

\subsection{Kết quả khảo sát khả năng hình thành bào tử}

Khả năng hình thành bào tử giúp các chủng vi khuẩn probiotic tồn tại tốt hơn dưới tác động của dịch tiêu hoá trong phần trên của đường tiêu hoá. Ngoài ra, đặc tính hình thành bào tử giúp dễ dàng bảo quản và sử dụng các chủng vi khuẩn probiotic trong sản xuất công nghiệp. Sự hình thành bảo tử phụ thuộc vào các điều kiện môi trường như $\mathrm{pH}$, nhiệt độ, hoạt độ nước, chất kích thích, thành phần dinh dưỡng, đặc điểm sinh trưởng của vi khuẩn. Kết quả khảo sát khả năng hình thành bào tử bằng phương pháp xử lý nhiệt ở $40^{\circ} \mathrm{C}, 50^{\circ} \mathrm{C}, 60^{\circ} \mathrm{C}$ trong các khoảng thời gian 12 giờ được trình bày trong Bảng 3.

Bảng 3: Khả năng hình thành bào tử của các chủng vi khuẩn phân lập từ đường tiêu hoá gà ở các mức xử lý nhiệt khác nhau trong 12 giờ.

\begin{tabular}{cccc}
\hline \multirow{2}{*}{ Chủng vi khuẩn } & \multicolumn{3}{c}{ Tỉ lệ hình thành bào tử (\%) } \\
\cline { 2 - 4 } C19 & $0,0065^{\mathrm{c}} \pm 0,0005$ & $20,04^{\mathrm{c}} \pm 2$ & $60^{\circ} \mathrm{C}$ \\
\hline C31 & $0,005^{\mathrm{b}} \pm 0,0005$ & $14,71^{\mathrm{b}} \pm 1,1$ & $85,24^{\mathrm{c}} \pm 1$ \\
C38 & $0,0024^{\mathrm{a}} \pm 0,0001$ & $5,22^{\mathrm{a}} \pm 0,1$ & $78,24^{\mathrm{b}} \pm 1,1$ \\
C43 & $0,0015^{\mathrm{a}} \pm 0,0001$ & $7,33^{\mathrm{a}} \pm 1,1$ & $80,32^{\mathrm{a}} \pm 2$ \\
C47 & $0,0244^{\mathrm{a}} \pm 0,0008$ & $7,44^{\mathrm{a}} \pm 0,45$ & $79,27^{\mathrm{a}} \pm 1,6$ \\
\hline
\end{tabular}

Các chữ khác nhau đi kèm giá trị trung bình trong cùng cột biểu thị sự khác biệt có ý nghĩa thống kê ở mức $P$-values $\leq 0,05$

Kết quả xử lý nhiệt để kích thích hình thành bảo tử đã xác định cả 5 chủng vi khuẩn phân lập từ ruột gà đều có khả năng hình thành bào tử. Ở mức nhiệt xử lý $40^{\circ} \mathrm{C}$, tỉ lệ hình thành bào tử rất thấp ở tất cả các chủng. Khi nhiệt độ tăng lên, tỉ lệ bảo tử hình thành cũng tăng theo, đạt từ $5-20 \%$. Ở mức nhiệt $60^{\circ} \mathrm{C}$, tỉ lệ bảo tử hình thành đạt trên $78 \%$ ở các chủng, đặc biệt chủng C19 có tỉ lệ hình thành bảo tử lên đến $95 \%$, cao hơn 
hẳn so với các chủng khác. Trong tất cả các điều kiện xử lý, chủng C38 có tỉ lệ hình thành thấp nhất so với các chủng khác (Bảng 3).

Các công bố của Setlow và Kornberg (1970) và Setlow (2003) cho thấy các chủng vi khuẩn Bacillus sp. cho tî lệ hình thành bảo tử cao nhất khi xử lý nhiệt ở $50^{\circ} \mathrm{C}$ trong 24 giờ $[7,20]$. Nghiên cứu của Casula và Cutting (2002) cho thấy tổng số bào tử Bacillus subtilis đạt cao nhất trong thời gian 6 giờ $\left(3.03 \times 10^{8}\right.$ bào tử $/ \mathrm{ml}$ ) khi nuôi ủ ở nhiệt độ $55^{\circ} \mathrm{C}$ trong môi trường DSM [21]. Đối với mỗi chủng vi khuẩn khác nhau, điều kiện kích thích hình thành bào tử là khác nhau, do trong nghiên cứu này khảo sát ảnh hưởng của nhiệt độ đối với sự hình thành bảo tử có thể chưa phải là tối ưu đối với tất cả các chủng vi khuẩn.

\subsection{Kết quả định danh các chủng vi khuẩn probiotic}

Vùng trình tự gen $16 \mathrm{~S}$ rRNA của các chủng vi khuẩn được khuếch đại bằng $\mathrm{PCR}$ và giải trình tự. Với cặp mồi sử dụng cho thấy đã khuếch đại được vùng gen này ở tất cả các chủng vi khuẩn. Kích thước đoạn khuếch đại khoảng 350-400 bp (Hình 5, Bảng 1 phụ lục).

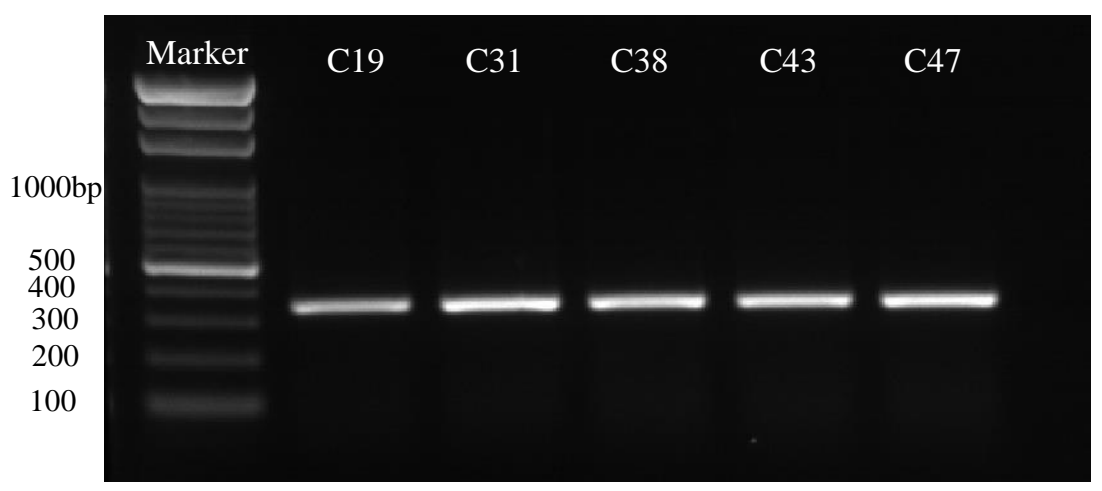

Hình 5: Kết quả điện di sản phẩm PCR khuếch đại vùng gen 16S rRNA của các chủng vi khuẩn phân lập từ ruột gà. Lane 1: DNA marker; lane 2 đến lane 6: sản phẩm PCR vùng gen $16 \mathrm{~S}$ rRNA của các chủng vi khuẩn lần lượt C19, $\mathrm{C} 31, \mathrm{C} 38, \mathrm{C} 43$ và $\mathrm{C} 47$

Đoạn trình tự gen 16S rRNA của các chủng vi khuẩn được sử dụng để xây dựng cây phát sinh loài, kết hợp với vùng trình tự gen $16 \mathrm{~S}$ rRNA của 18 chủng vi khuẩn tham chiếu (Hình 6).

Phân loài các chủng vi khuẩn trên cây phát sinh loài dựa vào chỉ số bootstrap tương ứng với mỗi nhánh. Chỉ số bootstrap càng cao thì mức độ tin cậy của chủng vi khuẩn cần định danh tương đồng với chủng vi khuẩn trên cùng một nhánh càng lớn. Theo Hillis và Bull (1993), mức độ tin cậy của phân tích phát sinh loài dựa vào chỉ số bootstrap được quy ước gồm: chỉ số bootstrap < 65 : mức độ tin cậy thấp; $65 \leq$ chỉ số bootstrap < 85: mức độ tin cậy trung bình; chỉ số bootstrap $\geq 85$ : mức độ tin cậy cao [22]. Kết quả phân tích từ cây phát sinh loài của chủng $\mathrm{C} 19$ cho thấy cùng nhánh với chủng Bacillus cereus với chỉ số bootstrap là 59 , mức độ tin cậy thấp. Chủng $\mathrm{C} 31$ nằm cùng nhánh với chủng Bacillus subtilis với chỉ số bootstrap 89 , có mức độ tin cậy cao. Chủng $\mathrm{C} 38$ nằm cùng nhánh với chủng Bacillus mycoides với chỉ số bootstrap 70 , có mức độ tin cậy trung bình. Chủng $\mathrm{C} 43$ nằm cùng nhánh với chủng Bacillus megaterium với chỉ số bootstrap 70, có mức độ tin cậy trung bình. Chủng $\mathrm{C} 47$ nằm cùng nhánh với chủng Bacillus licheniformis với chỉ số bootstrap là 100 , có mức độ tin cậy cao (Hình 6). Kết quả giải trình tự cho thấy cả 5 chủng nghiên cứu đều thuộc chi Bacillus. Điều này cũng phù hợp với các nghiên cứu của Nguyễn Lâm Đoàn và Nguyễn Hoàng Anh (2018) [23], Darland và Brock (1971) [24], Köhle et al. (2002) [25], và Yi và Setlow (2010) [26] khi chứng minh rằng các chủng vi khuẩn Bacillus đều có mặt trong trong đường ruột của người và vật nuôi. 


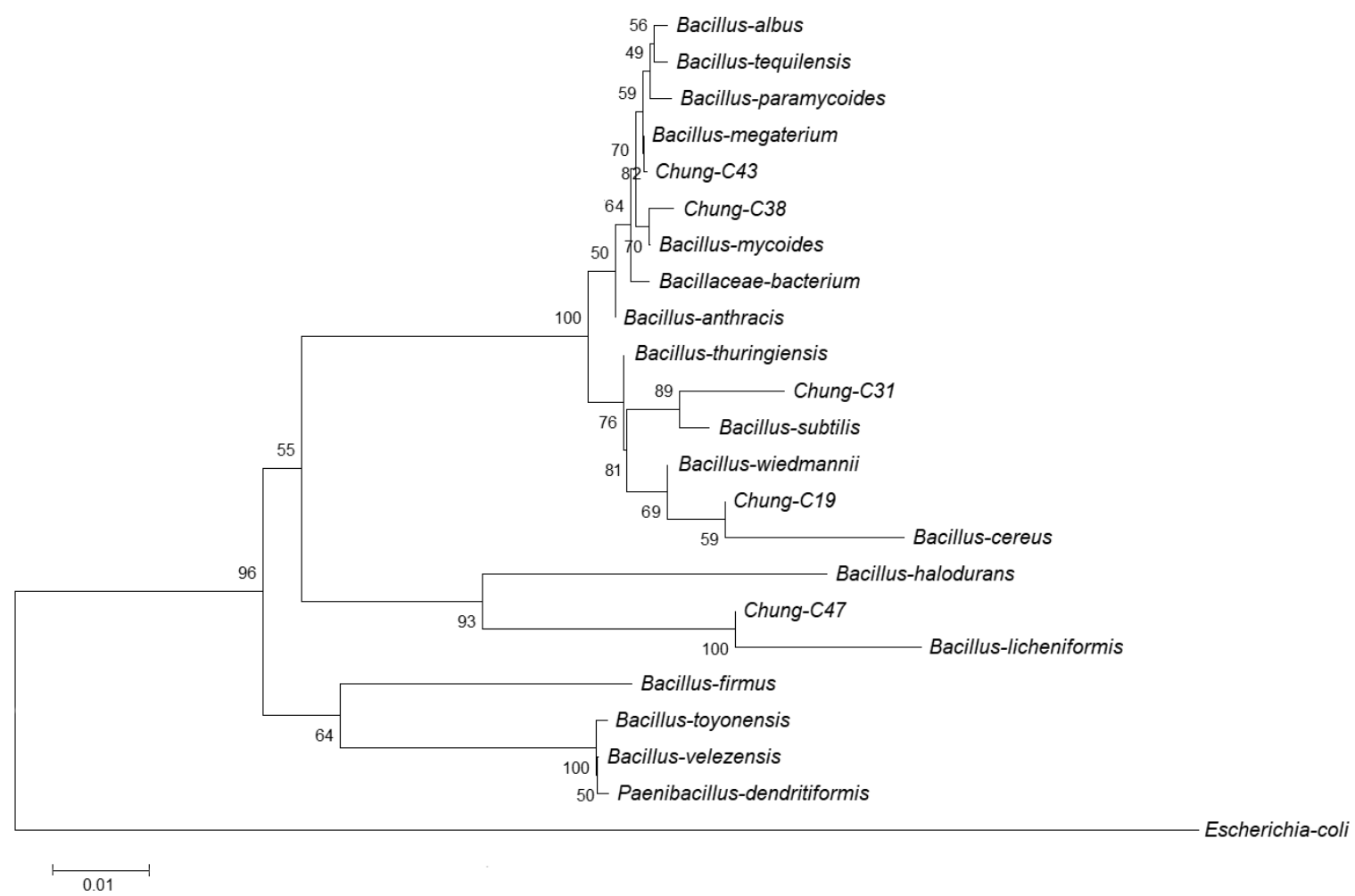

Hình 6: Cây phát sinh loài có gốc neighbor-joining của các chủng vi khuẩn $\mathrm{C} 19, \mathrm{C} 31, \mathrm{C} 38, \mathrm{C} 43$ và $\mathrm{C} 47$. Tỉ lệ xích biểu thị số biến đổi tại mỗi vị trí.

\section{KẾT LUẬN}

Từ 50 chủng vi khuẩn phân lập từ đường tiêu hoá của gà, nghiên cứu này đã khảo sát đặc tính probiotic, từ đó tuyển chọn được 5 chủng vi khuẩn có đặc tính phù hợp nhất. Cả 5 chủng tuyển chọn đều thuộc chi Bacillus, là chi phổ biến nhất với số lượng loài có đặc tính probiotic phong phú nhất. Kết quả của nghiên cứu là tiền đề để ứng dụng các chủng vi khuẩn này trong sản xuất chế phẩm probiotic sử dụng trong chăn nuôi.

\section{TÀI LIẾU THAM KHẢO}

[1] R. Fuller, Probiotics in man and animals, Journal of applied microbiology, vol. 66, no. 5, pp. 365-378, 1989.

[2] M. V. Schrezenmeir, Probiotics, prebiotics, and synbiotics - approaching a definition, The American journal of clinical nutrition, vol. 73, no. 2, pp. 361s-364s, 2001.

[3] World Health Organization, Guidelines for the evaluation of probiotics in food, report of a joint FAO/WHO working group on drafting guidelines for the evaluation of probiotics in food, London, Ontario, Canada, 2014.

[4] J. A. Patterson and K. M. Burkholder, Application of prebiotics and probiotics in poultry production, Poultry science, vol. 84, no. 4, pp. 627-631, 2003.

[5] S. Shivaramaiah, N.R. Pumford, M.J. Morgan, R.E. Wolfenden, A.D. Wolfenden, A. Torres-Rodríguez, B.M. Hargis, G. Téllez, Evaluation of Bacillus species as potential candidates for direct-fed microbials in commercial poultry, Poultry Science, vol. 90, no. 7, pp. 1574-1580, 2011.

[6] L. McFarland, The nephelometer: an instrument for estimating the number of bacteria in suspensions used for calculating the opsonic index and for vaccines. Jama, vol. XLIX, no. 14, pp.1176-1178, 1907 
[7] P. Setlow and A. Kornberg, Biochemical studies of bacterial sporulation and germination, The journal of biological chemistry, vol. 245, no. 14, pp. 3645-3652, 1970.

[8] J. M. Omar, Y. M. Chan, M. L. Jones, S. Prakash, P. J. H. Jones, Lactobacillus fermentum and Lactobacillus amylovorus as probiotics alter body adiposity and gut microflora in healthy persons, Journal of functional foods, vol. 5, no. 1, pp. 116-123, 2013.

[9] J. Behnsen, E. Deriu, M. Sassone-Corsi, M. Raffatellu, Probiotics: properties, examples, and specific applications, Cold Spring Harbor Perspectives in Medicine, vol. 3, no. 3, pp. a010074, 2013.

[10] M. L. Marco, S. Pavan, M. Kleerebezem, Towards understanding molecular modes of probiotic action, Current Opinion in Biotechnology, vol. 17, no. 2, pp. 204-210, 2006.

[11] M. L. Cross, A. Ganner, D. Teilab, L. M. Fray, Patterns of cytokine induction by gram-positive and gram-negative probiotic bacteria, FEMS Immunology \& Medical Microbiology, vol. 42, no. 2, pp.173-180, 2004

[12] W. Tee, R. Nazaruddin, Y. Tan, and M. Ayob, Effects of encapsulation on the viability of potential probiotic Lactobacillus plantarum exposed to high acidity condition and presence of bile salts, Food Science and Technology International, vol. 20, no. 6, pp. 399-404, 2014.

[13] B. Hyronimus, C. L. Marrec, A. H. Sassi, A. Deschamps, Acid and bile tolerance of spore-forming lactic acid bacteria, International Journal of Food Microbiology, vol. 61, no. 2-3, pp. 193-197, 2000.

[14] A. K. Patel, J. J. Ahire, S. P. Pawar, B. L. Chaudhari, S. B. Chincholkar, Comparative accounts of probiotic characteristics of Bacillus spp. isolated from food wastes, Food Research International, vol. 42, no. 4, pp. 505-510, 2009.

[15] M.S. Shin, S. K. Han, A. R. Ji, K. S. Kim, W. K. Lee, Isolation and characterization of bacteriocin-producing bacteria from the gastrointestinal tract of broiler chickens for probiotic use, Journal of applied microbiology, vol. 105, no. 6, pp. 2203-2212, 2008.

[16] W. Ding and N. Shah, Acid, bile, and heat tolerance of free and microencapsulated probiotic bacteria, Journal of Food Science, vol. 72, no. 9, pp. M446-M450, 2007.

[17] X. Pan, F. Chen, T. Wu, H. Tang, Z. Zhao, The acid, bile tolerance and antimicrobial property of Lactobacillus acidophilus NIT, Food Control, vol. 20, no. 6, pp. 598-602, 2009.

[18] Nguyễn Văn Thanh và Trần Thu Hoa, Khảo sát khả năng chịu đựng acid, muối mật và kháng sinh của một số vi sinh vật là nguyên liệu sản xuất probiotic đường uống, Tạp chi dược học, số 378, trang 32-35, 2007.

[19] Trần Quốc Việt, Bùi Thị Thu Huyền, Dương Văn Hợp và Vũ Thành Lâm, Phân lập, tuyển chọn và đánh giá một số đặc tính probiotics của các vi sinh vật hữu ích để sản xuất chế phẩm probiotics dùng trong chăn nuôi, Tạp chí Khoa Học Công Nghệ chăn nuôi, số 16, trang 1-12, 2009.

[20] P. Setlow, Spore germination, Current opinion in microbiology, vol. 6, no. 6, pp. 550-556, 2003.

[21] G. Casula and S. M. Cutting, Bacillus probiotics: spore germination in the gastrointestinal tract. Applied environmental microbiololy, vol. 68, no. 5, pp. 2344-2352, 2002.

[22] D. M. Hillis and J. J. Bull, An empirical test of bootstrapping as a method for assessing confidence in phylogenetic analysis, Systematic Biology, vol. 42, no. 2, June 1993, pp. 182-192, 1993

[23] Nguyễn Thị Lâm Đoàn và Nguyễn Hoàng Anh, Bacillus có tiềm năng probiotic từ ruột gà, Tạp chí khoa học nông nghiệp Việt Nam, tập 16, số 7, trang 689-697, 2018. 
[24] G. Darland and T. D. Brock, Bacillus acidocaldarius sp. nov., an acidophilic thermophilic spore-forming bacterium, Microbiology, vol. 67, no. 1, pp. 47-49, 1971.

[25] H. Köhler, S. Donarski, B. Stocks, A. Parret, C. Edwards and H. Schroten, Antibacterial characteristics in the feces of breast-fed and formula-fed infants during the first year of life, Journal of Pediatric Gastroenterology and Nutrition, vol. 34, no. 2, pp.188-193, 2002.

[26] X. Yi and P. Setlow, Studies of the commitment step in the germination of spores of Bacillus species, Journal of bacteriology, vol. 192, no. 13, pp. 3424-3433, 2010.

\section{PHỤ LỤC}

Bảng 1 phụ lục: Trình tự vùng gen $16 \mathrm{~S}$ rRNA của các chủng vi khuẩn phân lập từ đường tiêu hoá gà

\begin{tabular}{|c|c|}
\hline Chủng vi khuẩn & Trình tự vùng gen $16 \mathrm{~S}$ rRNA \\
\hline \multirow{7}{*}{ C19 } & CAGCAGTAGTGAATCTTCCACAATGGACGAAAGTCTGACGGAGCAACGCCGCGTGA \\
\hline & GTGATGAAGGCTTTCGGGTCGTAAAACTCTGTTGTTAGGGAAGAACAAGTGCTAGTT \\
\hline & GAATAAGCTGGCACCTTGACGGTACCTAACCAGAAAGCCACGGCTAACTACGTGCC \\
\hline & AGCAGCCGCGGTAATACGTAGGTGGCAAGCGTTATCCGGAATTATTGGGCGTAAAG \\
\hline & CGCGCGCAGGTGGTTTCTTAAGTCTGATGTGAAAGCCCACGGCTCAACCGTGGAGG \\
\hline & GTCATTGGAAACTGGGAGACTTGAGTGCAGAAAAGGAAAGTGGAATTCCATGTGTA \\
\hline & GCGGTGGAATAA \\
\hline \multirow{6}{*}{$\mathrm{C} 31$} & ТСТTCCACAATGGACGAAAGTCTGACGGAGCAACGCCGCGTGAGTGATGAAGGCTT \\
\hline & TCGGGTCGTAAAACTCTGTTGTTAGGGAAGAACAAGTGCTAGTTGAATAAGCTGGC \\
\hline & ACCTTGACGGTACCTAACCAGAAAGCCACGGCTAACTACGTGCCAGCAGCCGCGGT \\
\hline & AATACGTAGGTGGCAAGCGTTATCCGGAATTATTGGGCGTAAAGCGCGCGCAGGTG \\
\hline & GTTTCTTAAGTCTGATGTGAAAGCCCACGGCTCAACCGTGGAGGGTCATTGGAAACT \\
\hline & GGGAGACTTGAGTGCAGAAGAGGAAAGTGGAATTCCATGTGTA \\
\hline \multirow{7}{*}{$\mathrm{C} 38$} & TTAACCATTGGGGATTTTTCACAAATGGGGAAAGTTTGGAGGCAGCCAGCCGGCGG \\
\hline & AGTGATGAAGGGCTTTGGGTTGTTAAAGTTTGTCATTGGGGAGGACAAGGTTGATGC \\
\hline & GAATATCATCGTACCTTGACGGTACCTACCCAGAAAGCCACGGCTAACTACGTGCCA \\
\hline & GCAGCCGCGGTAATACGTAGGTGGCAAGCGTTATTCGGAATTATTGGGCGTAAAGC \\
\hline & GCACGCAGGCGGTTTATTAAGTTTGATGTGAAATCCCCCGGCTCAACCGGGGAGGG \\
\hline & GCATGTGAAACTGGGGAAACTTGATGGCGTAAAAGGAGGTTGAATTCCCTGTGTTA \\
\hline & CGGTGGAATTA \\
\hline \multirow{7}{*}{$\mathrm{C} 43$} & AGCAGTAGTGGATCTTCCACAATGGACGAAAGTCTGACGGAGCAACGCCGCGTGAG \\
\hline & TGATGAAGGCTTTCGGGTCGTAAAACTCTGTTGTTAGGGAAGAACAAGTGCTAGTTG \\
\hline & AATAAGCTGGCACCTTGACGGTACCTAACCAGAAAGCCACGGCTAACTACGTGCCA \\
\hline & GCAGCCGCGGTAATACGTAGGTGGCAAGCGTTATCCGGAATTATTGGGCGTAAAGC \\
\hline & GCGCGCAGGTGGTTTCTTAAGTCTGATGTGAAAGCCCACGGCTCAACCGTGGAGGG \\
\hline & TCATTGGAAACTGGGAGACTTGAGTGCAGAAGAGGAAAGTGGAATTCCATGTGTAG \\
\hline & CGGTGGAAT \\
\hline \multirow{7}{*}{$\mathrm{C} 47$} & AGCAGTAGGGAATCTTCCACAATGGACGAAAGTCTGACGGAGCAACGCCGCGTGAG \\
\hline & TGATGAAGGTTTTCGGATCGTAAAGCTCTGTTGTTAGGGAAGAACAAGTACCGTTCG \\
\hline & AATAGGGCGGTACCTTGACGGTACCTAACCAGAAAGCCACGGCTAACTACGTGCCA \\
\hline & GCAGCCGCGGTAATACGTAGGTGGCAAGCGTTGTCCGGAATTATTGGGCGTAAAGG \\
\hline & GCTCGCAGGCGGTTTCTTAAGTCTGATGTGAAAGCCCCCGGCTCAACCGGGGAGGG \\
\hline & TCATTGGAAACTGGGGAACTTGAGTGCAGAAGAGGAGAGTGGAATTCCATGTGTAG \\
\hline & CGGTGGAAT \\
\hline
\end{tabular}

Ngày nhận bài: 11/08/2020

Ngày chấp nhận đăng:10/12/2020 